\title{
Andrija Kornhauser-Constantine Zervos' actinic prophiria in Man treated with Talc de Trimouns-Luzenac and Oxymyrsine pungens Bubani glyceric extract
}

\author{
Piotr Brzeziński', Lorenzo Martini ${ }^{1,2}$
}

${ }^{1}$ University of Siena, Department of Pharmaceutical Biotechnologies, Via A. Moro 2, 53100 Siena, Italy, ${ }^{2}$ C.R.I.S.M.A. Inter

University Centre for Researched Advanced Medical Systems

Corresponding author: Prof. Lorenzo Martini, E-mail: martini36@unisi.it

\begin{abstract}
The AA, after having studied and published prior a paper regarding the poikiloderma of Civatte, have attempted to cure owing to a cosmetic remedy the Andrija Kornhauser-Constantine Zervos' actinic prophiria, that is a more severe dermatose evoked by the prolonged use of pure essential oils when spread directly on face and neck skin and after exposure to sun. They have ideated a paste containing talc and Ruscus aculeatus glyceric extract and other vasoconstrictor agents and lypophilic vitamins. The volunteer who decided to undergo the experimentations had to follow several stratagems, a bit complicate but that resulted very efficient and right to cure definitively the syndrome of Andrija Kornhauser-Constantine Zervos' actinic prophiria.
\end{abstract}

Key words: Andrija Kornhauser-Constantine Zervos' actinic prophiria; Pure essential oils; Talc de Trimouns-Luzenac; Vit A; Vit E; Vit F

Sir,

All substances that are considered photosensitizers are fluorescent ones: this mean that they are natural or chemical elements that after having absorbed some exciting radiation, are able to modify it and to cease newly it in the guise of one or more radiations characterized by major wavelength and minor frequence of the absorbed one previously $[1,2]$.

Substances that are photosensitizers may be absorbed orally and/or topically and all of them may provoke, under the sun rays of whichever wavelength or frequence, the Andrija Kornhauser-Constantine Zervos' actinic prophiria.

Amongst the oral photosensitizers one can number porphirins, hemocyanins (tetrapyrrolic molecules) retrievable in many crustaceans and/or shellfish.
Amongst the photosensitizers that act assumed both orally or topically, it is possible to find phylloeritrines (contained in chlorophyll), furocoumarines (Coronilla glauca, Ficus carica, Phebalium argenteum, Zanthoxylum flavum), xanthotoxins (Angelica arhangelica. Amni majus, Fagara xanthoxyloides, Ruta chalepensis, Ruta montana), bergaptens (Apium graveolens, Citrus acida, Citrus bergamia, Heracleum gigantum, Ligusticum acutilobum, Pastinaca sativa,Petrosilum sativum, Pimpinella saxifrage), oxypeucedanines (Imperatoria ostruthium), quinolones (Chincona calisaya), antraquinones (rhubarb, aloe faerox, sena, cascara sagrada, frangula).

Amongst the topical photosensitizers one may number all the forage containing hypericin, Phagopyrines (Polygonum fagopyron, Trifolium hybridum, Medicago sativa, Lupinus coeruleus) and this situation may occur when people love to lie on the grass during the

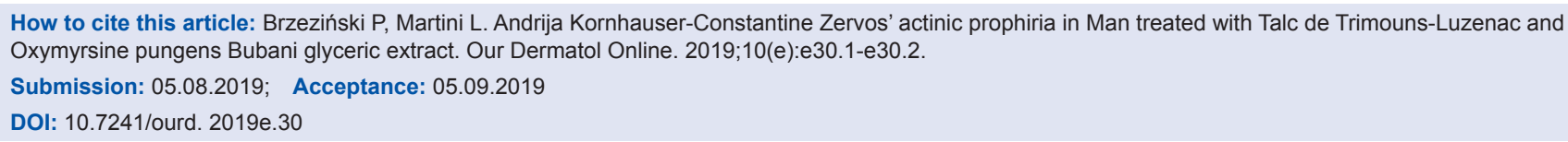


hot seasons and all the oil derivatives, as coal and naphtalenes.

The AA has recruited a volunteer, a man 42 y. old, living at Cyprus and who has been using to spread pure essential oils to his face and neck (ambergris, opoponax, lemongrass, ambrette,musk) and drive the car 4 hours a day to go to work and come back home under the sun that filtered from the car windows and contracted a severe actinic porphyria, with itch, red and leathery skin, bumps and feeling of rubbery epidermis, and all these are the symptoms of the Andrija KornhauserConstantine Zervos' actinic prophiria [3].

In a recent paper the same AA had written about the poikiloderma of Civatte [4] they used shellac and Lycopus extract to treat the syndrome and revealed optimal results after 2 weeks of applications of the ointment, they now have decided to use an inert powder apt to behave as a patch or salbe, some natural vasoconstrictor agents and three lypophilic vitamins $(\mathrm{A}, \mathrm{E}$ and $\mathrm{F})$.

The real formula was the following: Talc de TrimounsLuzenac; Ruscus aculeatus glyceric extract; Achillea millefolium glyceric extract; Ginkgo biloba glyceric extract; Vit A; Vit E; Vit F.

The applications lasted 2 weeks.

The volunteer used to spread the salbe only before to go to bed and did not wash his face and neck, this because during the day sebum of the skin permits to have an oily epidermis and so the paste could penetrate better through the barrier of stratum corneum, by diachisis (Hyppocrates used to refer: Similes cum similibus and so an oily phase can be absorbed better by an oily surface, not cleansed at all).

When he woke up in the morning he washed skin and neck with water and a toning lotion (containing
Arctium Lappa extract reputed an exceptional abstringent agent) and used to spread Argan oil mixed with petroleum jelly.

He did not use sunscreens and remained at home without expose to the sun for the 2 weeks of treatment.

The very first 4 days he felt a feeling of tingling when he spread the paste on his face and neck, but at $5^{\text {th }}$ day his face and neck were bleached and flesh-coloured and all bumps and scares disappeared as well.

He showed a real satisfaction for this remedy.

\section{Consent}

The examination of the patient was conducted according to the Declaration of Helsinki principles.

\section{REFERENCES}

1. Dadwal S, Deol H, Kumar M, Bhalla V. AIEE Active Nanoassemblies of Pyrazine Based Organic Photosensitizers as Efficient MetalFree Supramolecular Photoredox Catalytic Systems. Sci Rep. 2019;9:11142.

2. Nigam PK. Antifungal drugs and resistance: Current concepts. Our Dermatol Online. 2015;6:212-21.

3. Zervos C, Andersen FA, Kornhauser A. Photochemical toxicity: toxic, allergic, and carcinogenic aspects with emphasis on predicting effects in humans: proceedings of the seventh in the series of Food and Drug Administration Science Symposia, held at the Uniformed Services University of the Health Sciences, Bethesda, Maryland, March 16-17, 1981.Published by Rockville,Md:US Dept of Health and Human Service, FDA, 1982.

4. Brzezinski P, Martini L. A nice stratagem to treat poikiloderma of Civatte, evoked by fragrances and essential oils, by means of a resin that is commonly employed to finish mandolins and Maggiolini's furniture. Our Dermatol Online. 2019;10(e):e6.1-e6.3.

Copyright by Piotr Brzeziński, et al. This is an open-access article distributed under the terms of the Creative Commons Attribution License, which permits unrestricted use, distribution, and reproduction in any medium, provided the original author and source are credited.

Source of Support: Nil, Conflict of Interest: None declared. 